\title{
APP physiological and pathophysiological functions: insights from animal models
}

\author{
Qinxi Guo ${ }^{1,2}$, Zilai Wang ${ }^{1}$, Hongmei Li $^{1}$, Mary Wiese ${ }^{1,3}$, Hui Zheng ${ }^{1,2,3}$ \\ ${ }^{1}$ Huffington Center on Aging, Baylor College of Medicine, One Baylor Plaza, BCM:MS230, Houston, TX 77030, USA; ${ }^{2}$ Program in \\ Translational Biology and Molecular Medicine, Houston, TX 77030, USA; ${ }^{3}$ Department of Molecular and Human Genetics, Baylor \\ College of Medicine, Houston, TX 77030, USA
}

The amyloid precursor protein (APP) has been under intensive study in recent years, mainly due to its critical role in the pathogenesis of Alzheimer's disease (AD). $\beta$-Amyloid (A $\beta$ ) peptides generated from APP proteolytic cleavage can aggregate, leading to plaque formation in human AD brains. Point mutations of APP affecting A $\beta$ production are found to be causal for hereditary early onset familial AD. It is very likely that elucidating the physiological properties of APP will greatly facilitate the understanding of its role in AD pathogenesis. A number of APP loss- and gainof-function models have been established in model organisms including Caenorhabditis elegans, Drosophila, zebrafish and mouse. These in vivo models provide us valuable insights into APP physiological functions. In addition, several knock-in mouse models expressing mutant APP at a physiological level are available to allow us to study AD pathogenesis without APP overexpression. This article will review the current physiological and pathophysiological animal models of APP.

Keywords: Alzheimer's disease; APP; A $\beta$; knock-in; animal models

Cell Research (2012) 22:78-89. doi:10.1038/cr.2011.116; published online 19 July 2011

\section{Introduction}

The amyloid precursor protein (APP) is one of the most intensively studied molecules since it was first cloned more than 20 years ago [1-3]. A notable feature of APP is that it undergoes finely regulated secretase cleavage processing (Figure 1). In general, the $\alpha$-secretase or $\beta$-secretase cleaves the APP extracellular domain generating the soluble $\mathrm{N}$-terminal fragments APPs $\alpha$ or APPs $\beta$ and the membrane-associated $\mathrm{C}$-terminal fragments $\mathrm{CTF} \alpha$ and CTF $\beta$, respectively. CTF $\alpha$ or CTF $\beta$ will further be cleaved by the $\gamma$-secretase within the transmembrane domain releasing the $\mathrm{p} 3$ peptide or $\beta$-amyloid $(\mathrm{A} \beta)$ peptide. Following $\gamma$-secretase cleavage, both CTFs will also release the APP intracellular domain (AICD) into the cytoplasm. $\alpha$-Secretase-mediated APP cleavage prevents $\mathrm{A} \beta$ production, and thus is called the non-amyloidogenic pathway, whereas the $\beta$-secretase-mediated APP cleavage

Correspondence: Hui Zheng

Tel: +1 713-798-1568; Fax: +1 713-798-1610

E-mail: huiz@bcm.edu generates $A \beta$ peptides and is called the amyloidogenic pathway. However, recent studies showed that APP proteolytic cleavage could be more complicated than above (reviewed by Chow et al. [4]). For instance, besides the $\gamma$-site cleavage of the CTFs by $\gamma$-secretase, CTFs may also undergo ' $\varepsilon$-site' cleavage near the cytoplasmic membrane boundary of APP [5].

The normal physiological functions of APP have raised curiosity, since it belongs to an evolutionarily conserved protein family (Figure 2) and combined deficiency of APP and its homologs leads to early postnatal lethality in mammals $[6,7]$. A number of APP loss-offunction and gain-of-function in vivo models have been established and characterized in different model organisms, including Caenorhabditis elegans, Drosophila, zebrafish and mouse. Studies from different species indicate conservation of function between APP family members, including roles in cell adhesion, neuron migration and synaptogenesis.

Enormous scientific efforts have been put into APPrelated studies mainly because of its vital pathophysiological functions in Alzheimer's disease (AD). AD is the leading cause of dementia in the aged population. There 


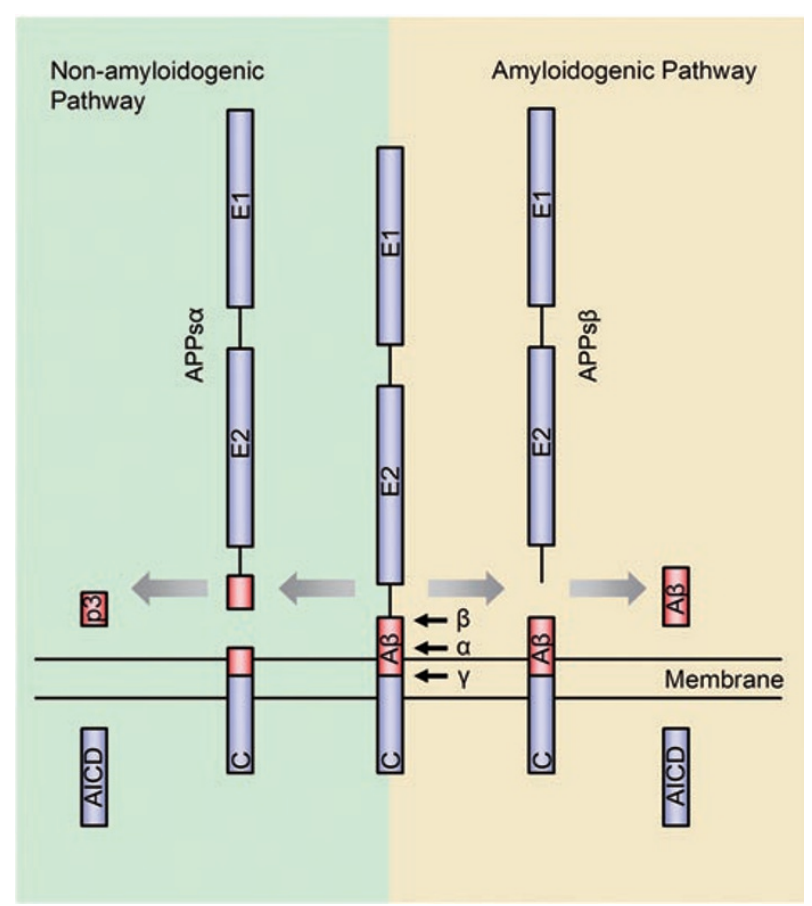

Figure 1 APP amyloidogenic and non-amyloidogenic processing pathways (not drawn to scale). The $A \beta$ domain is highlighted in red. For simplicity, only one cleavage site is shown for each enzyme.

are three pathological hallmarks of AD: extracellular amyloid plaques, intracellular neurofibrillary tangles and neuronal degeneration including synapse loss. Amyloid plaques are extracellular deposits primarily composed of $\mathrm{A} \beta$ peptides that are derived from proteolytic cleavage of APP and associated with other components (reviewed by Armstrong et al. [8]). The pathogenic mechanism of AD is very controversial, however, the $A \beta$ cascade hypothesis is currently most favored. This hypothesis states that the excessive $A \beta$ peptides generated from mis-regulated cleavage of APP or impaired clearance play a central role in $\mathrm{AD}$ [9]. While the vast majority of $\mathrm{AD}$ cases occur after 65 years of age, a small percentage of patients $(<5 \%)$ develop clinical symptoms before the age of 65 years due to autosomal dominant familial AD (FAD) mutations [10]. These mutations have been discovered in three different genes: APP, Presenilin 1 and 2 (PSEN1 and PSEN2). Most mutations in the $A P P$ and $P S E N$ (or $P S$ ) genes alter the production of $A \beta$ cleavage profiles, leading to accelerated amyloid pathology. Several lines of knock-in mice (KI) with $A P P$ FAD mutations have been generated in recent years, either by mutation of $A P P$ alone or in combination with PS1 mutations. Compared to traditional $\mathrm{AD}$ transgenic mice, which have been used extensively in the field, these KI models do not suffer from the confounding effects of APP overexpression and offer us a more physiologically relevant platform to investigate $\mathrm{AD}$ pathogenesis. We believe a review of these in vivo APP animal models will facilitate the understanding of $\mathrm{AD}$ pathogenesis in the context of APP physiology.

\section{Non-mammalian APP animal models}

\section{C. elegans}

The C. elegans homolog of APP, APL-1, is structurally similar to its mammalian counterpart and shares sequence homology in the N-terminal E1 and E2 domains and the intracellular C-terminal domain, which has the highest sequence conservation (Figure 2) [11]. There are no known coding region splice variants detected in APL-1, which most closely resembles the neuronal isoform of APP, APP695 [11]. However, APL-1 does not contain the amyloid- $\beta$ sequence, similar to the functionally redundant mammalian APP homologs APLP1 and APLP2 [11-14].

Nematode development includes four larval stages after each of which is a molt where a new, larger exoskeleton is formed to accommodate the growth of the larvae. In worms, loss of function of the single apl-1 gene leads to developmental arrest and lethality during the first larval stage (L1), likely due to a molting defect [15, 16]. Many of the apl-1-null worms arrest at the L1/L2 transition, unable to shed old cuticle and exhibiting massive internal degradation $[15,16]$. RNAi knockdown of apl-1 also leads to a molting defect, although less severe than the null mutant, as the worms exhibit loose cuticle primarily around the head beginning at the L3/L4 molt $[16,17]$. In addition to the molting defect, apl-1 knockdown leads to hypersensitivity to the acetylcholinesterase inhibitor aldicarb, signifying a defect in cholinergic neurotransmission [16]. The neuronal phenotype and the molting defect were found to be independent of one another, suggesting apl-1 contributes to multiple functions within the worm. However, more studies are needed to determine the mechanism of apl-1 regulation in each of these functions.

Structure-function studies have been performed in an attempt to identify functional domains of apl-1 through rescue of the apl-1-null lethality and molting defect. Surprisingly, both phenotypes were found to be rescued by either a C-terminal truncation of apl-1 or the soluble $\mathrm{N}$-terminus, showing that the highly conserved $\mathrm{C}$-terminus is not required for apl-1 function in the worm [15, 16]. This differs from the mammalian system in which the APP C-terminus is essential for viability on a nonredundant background (see discussion under ' $\mathrm{KI}$ models 


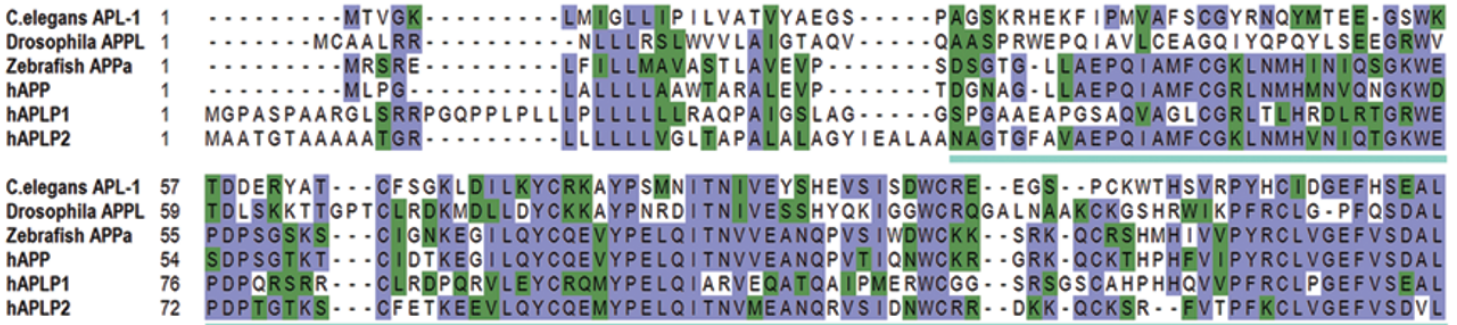

hAPLP2 72 PDPTGTKS.-.CFETKEEVLQYCQEMYPELQITNVMEANQRVS IDNWCRR - DKK-QCKSR - - FVTPFKCLVGEFVSDVL

C.elegans APL-1 130 QVPHDCQFS SHVNSRDQCNDYQHWKDEAGKQCKTKKSKGNKDMIVRSFAVLEPCALDMFTGVEFVCCPNDQTNKTDVQKTK Drosophila APPL 138 LVPEGCLFDH I HNASRCWPFVRWNQTGAAACQER....... GMQMRSFAMLLPCG ISVFSGVEFVCCPKHFKTDEIHVKKT Zebrafish APPa 129 LVPDKCKF LHQERMDMCESH HWHTVAKESCGDR........ SMN L HDYGMLLPCGIDRFRGVEFVCCP.ADAGKESESAAV hAPP 128 LVPDKCKF LHQERMDVCETHLHWHTVAKETCSEK........ ST NL HDYGMLLPCGIDKFRGVEFVCCPLAEESDNVDSADA hAPLP1 151 LVPEGCRFLHQERMDQCESSTRRHQEAQEACS SQ........ GL I L HSGMLLPCGSDRFRGVEYCCPPPGTPDPSGTAVG hAPLP2 144 LVPEKCQFFHKERMEVCENHQHWHTVVKEACLTQ....... GMTLYSYGMLLPCGVDQFHGTEYVCCPQTK I I GSVSKEEE

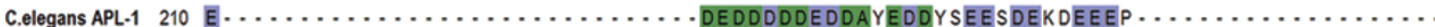
Drosophila APPL 212 DLPVMPAAQ INSANDELVMNDEDDSNDSNYSKDANEDOLDDEDDLMGDDEEDDMVADEAATAGGSPNTGSSGDS SGSLD Zebrafish APPa 202 EEDDSDVWWGGAEADYTENSMTRDAAAEPAVLEDDEDADEEEDEDQDGDGDRDEK IEEEE................. EEE hAPP $\quad 202$ EEDDSDVWWGGADTDYADG $\cdots$ SEDKVVEVAEEEEVAEVEEEEADDDEDDEDGDEVEEEAE $\cdots \cdots \cdots \cdots \cdots \cdots$

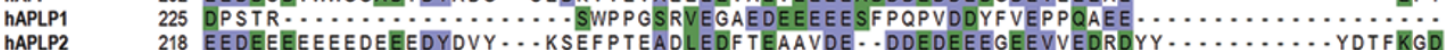

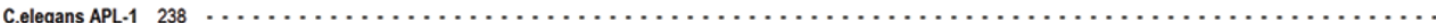
Drosophila APPL 292 DINAEYDSGEEGDNYEEDGÄGSESEAEVEÄSWDQSGGAKVVVSLKSDSS SPS SAPVAPAPEKAPVKSESVTSTPQL SA SAA Zebrafish APPa 265 ERTQSTSAALTSTTTTTTESVEEVVREVCFASAETGPCRAMLSRWYYVREERRCAPF I YGGCGGNRNNFESEEYCLSVCS hAPP 263 EEATERTTS IATTTTTTESVEEVVREVCSEQAETGPCRAMISRWYFDVTEGKCAPFFYGCGGNRNF DTEEYCMAVCG

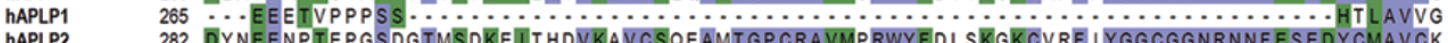

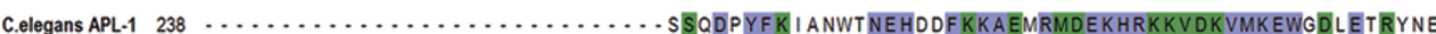
Drosophila APPL 372 AFVAANSGNSGTG................

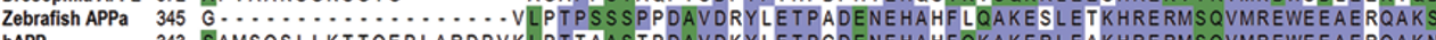
hAPP 343 SAMSQSLLKTTQEPLARDPVKLPTTAASTPDAVDKYLETPGDENEHAHFQKAKERLEAKHRERMSQVMREWEEAERQAKN hAPLP1 $283 \mathrm{~K}$.................... VTPTPRPTDGVD IYFGMPGEISEHEGFLRAKMDLEERRMRQ I NEVMREWAMADNQSKN

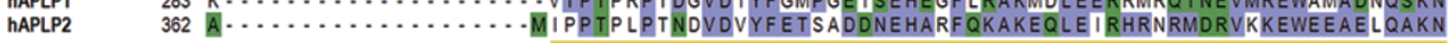

C.elegans APL-1 289 QKAKDPKGAEKFKSQMNARFQKTVSSLEEEHKRMRKE IEAVHEERVQAMLNEKKRDATHDYRQALATHVNKPNKHSVLQS Drosophila APPL 444 MRLADPKAAQSFKQRMTARF QTS SQALEEEGNAEKHQLAAMHQQRVLAHI NQRKREAMTCYTQA LTEQP..PNAHHVEKC Zebrafish APPa 406 LPRND......... KKAV I QHF QEKVEALEQESASERQQLVETHMARVEALLNDRRRLALESYLSALQADP. . PRPRHVFSL hAPP $\quad 423$ LPKAD.......... KKAVIQHFQEKVESLEQEAANERQQLVETHMARVEAMLNDRRRLALENY ITALQAVP...PRPRHVFNM hAPLP1 342 LPKAD.........RQALNEHFQS ILQTLEEQVSGERQRLVETHATRVIAL INDQRRAALEG LAALQADP.. PQAERVLLA

hAPLP2 422 LPKAE.........RQTLI IQHFQAMVKALEKEAASEKQQLVETHLARVEAMLNDRRRMALENYLAALQSDP..PRPHRILQA

C.elegans APL-1 369 LKAYIRAEEKDRMHTLNRYRHLLKADS .... KEAAAYKPTVIIHRLRYIDLRINGTLAMLRDF PDLEKYVRP IAVTYWKDY Drosophila APPL 522 LQKLLRALHKDRAHALAHYRHLLNSGGPGGLEAAASERPRT LERLID I DRAVNQSMTMLKRYPELSAK IAQLMNDYILAL $\begin{array}{lll}\text { Zesbafish APPa } & 477 & \text { LKKYVRAEQKDRQHTLKHFEHVRMVDP.... KKAAQIRPQVLTHLRV IEERMNQSLGLLYKVPGVADD IQDQVV.ELLQRE } \\ \text { hAPP } & 494 \text { LKKYVRAEQKDRQHTLKHFEHVRMVDP.... KKAAQIRSQVMTHLRV IYERMNQSLSLLYNVPAVAEE IQDEVDELLQKE }\end{array}$ $\begin{array}{lll}\text { hAPP } & 494 & \text { LKKYVRAEQKDRQHTLKHFEHVRMVDP.... KKAAQ IRSQVMTHLRV IYYERMNQS LSLLYNVPAVAEE IQDEVDELLLKE } \\ \text { hAPLP1 } & 413 \text { LRRYLRAEQKEQRHTLRHYQHVAAVP..... EKAQQMRFQVHTHLQV IEERVNQS LGLLDQNPHLAQELRPQIQELLHSE }\end{array}$ hAPLP1
hAPLP2

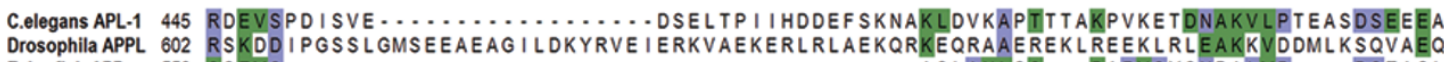

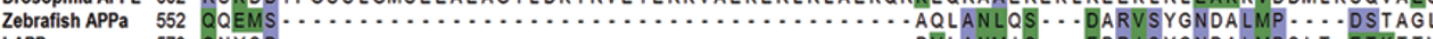

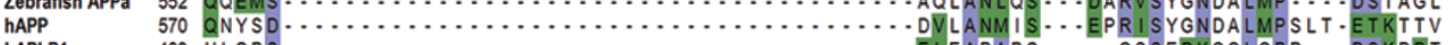

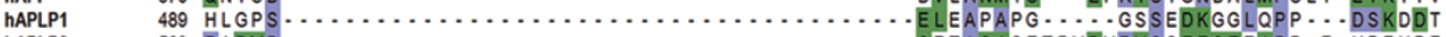
hAPLP2 $\quad 569$ RADMD $\ldots \ldots \ldots \ldots \ldots \ldots \ldots \ldots \ldots \ldots \ldots \ldots \ldots \ldots \ldots \ldots \ldots \ldots \ldots$ Q $\ldots \ldots$ IISETPVDVRVSSEESEEIPP.F.HPFHPF

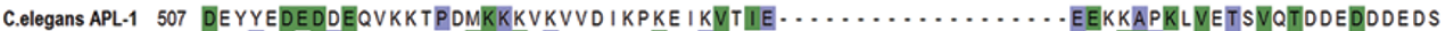
Drosophila APPL 682 QSQPTQSSTQSQAQQQQQEKS SL PGELGPDAALVTAANPNLETTKSEKDLSDTEYGEATVSSTKVQTVLPTVDDDAVQRA

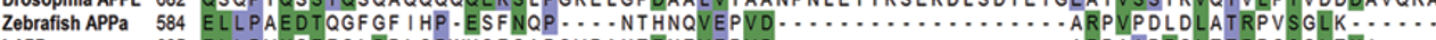

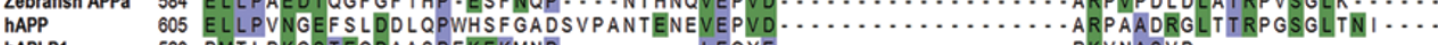

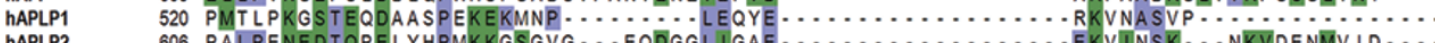

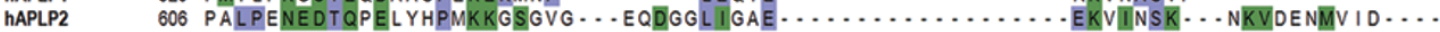

C.elegans APL-1 568 SSSTSSES DEDEDKN IKELRVD IEP I I DEPASFYRHDKLIQSPEVERSASSVFQPYVLASAMF ITAICIIAFAITNARRR Drosophila APPL 762 VEDVAAAVAHQEA EPQVQHFMTHDLGHRESSFSLRREFAQHAHAAKEGRNVYFTLSFAGIALMAAVFVGVAVAKWRT SRS

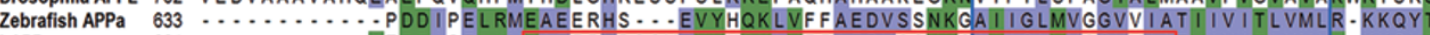
hAPP

hAPLP1

hAPLP2 $661 \cdots \cdots . . . . . . . .6$ TEE I SEVKMDAEFRHDSGYEVHHQKLVFFAEDVGS $555 \ldots \ldots \ldots \ldots \ldots \ldots$ RGFPFHSS ........... EIQRDELAPAGTGVS - REAVSGLLIMGAGGGSLIVLSMLLLRRKKPYG

C.elegans APL-1 648 RAMRGF IEVD - ...... VYYTPEERHVAGMQVNG YENPTYSFFDSKA.

Drosophila APPL 842 PHAQGFIEVDQNVTTHHPIVREEK IVPNMQ I NG YENPTYKYFEVKE.

Zebrafish APPa 698 SIIHHG IIEVDA........AVTPEERHLSKMQQNG YENPTYKFFEQMHN

hAPP 730 SI HHGVVEVDA.........AVTPEERHLSKMQQNGYENPTYKFFEQMQN

hAPLP1 611 A ISHGVVEVDP........MLTLEEQQLRELQRHGYENPTYRFLEERP.

Figure 2 Homology between APP family members. Comparison of protein sequences of C. elegans APL-1, Drosophila APPL, zebrafish APPa and the human APP family members reveals distinct areas of homology. Purple sequences indicate identical homology while green references similar amino acids. Homologous regions include the E1 domain (pale blue line), E2 domain (yellow line) and sequences within the C-terminus such as the conserved Thr site (arrow head) and YENPTY motif (black box). The transmembrane domain and $A \beta$ sequence are noted by the blue and red boxes, respectively. 
expressing distinct $A P P$ fragments') [18, 19]. Hornsten et al. [15] were unable to accomplish rescue using the Cterminus alone, indicating, together with the other rescue experiments, that the $\mathrm{N}$-terminus is the primary functional domain of APL-1 in the worm.

\section{Drosophila}

APPL is the APP homolog in Drosophila, and, like the worm homolog, does not contain the $\mathrm{A} \beta$ sequence (Figure 2). Appl-deficient flies are viable and fertile with no obvious phenotypes; however, these flies do have subtle behavioral defects, such as fast phototaxis impairment. This defect can be partially rescued by transgenic expression of either wild-type fly APPL or human APP, which demonstrates the functional conservation of APP between different species [20].

Subsequent loss and gain-of-function studies revealed more specific functions of APPL. APPL plays an important role in axonal transport, since either Appl deletion or its overexpression will cause axonal transport defects similar to kinesin and dynein mutants [21]. APPL is required for the development of neuromuscular junctions (NMJs), since $A p p l$ deletion leads to decreased NMJ bouton number, whereas Appl overexpression dramatically increases bouton number [22]. This activity can be explained by the formation of a potential complex including APPL, the APPL-binding protein $\mathrm{dX} 11$ /Mint, and the cell adhesion molecule FasII, which together can regulate synapse formation [23]. APPL also plays a role in the development of the Drosophila peripheral nervous system (PNS) as both Appl deletion and Appl RNAi leads to the loss of scutellar mechano-sensory organs (MSOs). Overexpression of human APP homologs in the fly leads to MSO Notch gain-of-function phenotypes, possibly through the interaction of the APP YENPTY motif with Numb/Pon and Dab [24].

APPL promotes post-developmental neurite arborization, which may be involved in brain injury response and repair. This function was revealed in a study showing that overexpression of human APP and APPL can induce post-developmental axonal arborization. This phenotype is dependent on the APP C-terminal domain and its interaction with the Abelson tyrosine kinase. Interestingly, similar to mammals, APPL is strongly upregulated after traumatic brain injury (TBI) in flies upon which APPLdeficient flies suffer a higher mortality rate compared to controls [25].

Overall, Appl loss and gain-of-function studies in Drosophila models offer us important insights into the physiological functions of APP and some of these findings have already been validated in mouse models.

\section{Zebrafish}

Zebrafish have two APP homologs, APPa and APPb. APPa is a 738-aa protein and contains the Kunitz protease inhibitor domain in the N-terminus, which resembles the human APP770 isoform. APPb is a 694aa protein, which is more similar to the human APP695 isoform [26]. The study of a transgenic zebrafish model expressing GFP under the appb promoter control reveals that the GFP is mainly expressed in subregions of brain, spinal cord and the developing vasculature of zebrafish embryos. The GFP expression level increases during development, and in adult transgenic zebrafish, GFP was abundantly expressed in the brain [27]. Though appa knockdown in zebrafish does not show any significant defects in development, appb knockdown animals show several early developmental deficits, including a shortened body axis, a short and curly tail and mild synopthalmia, which can be explained by defective convergentextension movements [26]. These defects can be largely rescued by human APP695 mRNA, partially rescued by human APPs $\alpha$ mRNA, but cannot be rescued by APP bearing the Swedish mutation, which leads to FAD in humans. It is interesting that this study indicates APP FAD mutations may not only contribute to $\mathrm{AD}$ pathogenesis during aging but also affect early development due to APP loss-of-function.

Though there are not many APP physiological function studies employing zebrafish, as a well-established model organism for vertebrate development, we expect to see more novel findings from the zebrafish system in the near future.

\section{APP models in mice}

To understand the physiological functions of APP and its family members, individual and combined mouse mutants of $A P P, A P L P 1$ and $A P L P 2$ have been generated. For $A P P$, there are two knockout (KO) alleles [28, 29], one hypomorphic allele [30], two conditional alleles [31, $32]$, four defined truncation KI alleles [18, 19, 33] and two C-terminal point mutation KI alleles reported [34, 35].

\section{$A P P, A P L P 1$ and $A P L P 2$ single $K O$ mice}

$A P P \mathrm{KO}$ mice are viable and fertile but suffer from various defects and abnormalities, such as reduced body and brain weight, decreased size of forebrain commissures, increased frequency and severity of corpus callosum agenesis [28, 30], reactive gliosis [28], increased sensitivity to kainate-induced seizures [36], increased copper and iron levels in the cerebral cortex and liver [37, 38], upregulated cholesterol and sphingomyelin levels 
in the brain [39] and decreased plasma glucose levels as well as hyperinsulinemia [40]. Behavioral studies revealed that $A P P \mathrm{KO}$ mice have decreased locomotor activity, reduced forelimb grip strength and deficits in the Morris water maze task as well as passive avoidance learning [41-43]. Electrophysiology studies show that these mice are also defective in long-term potentiation (LTP), which is associated with attenuated paired-pulse depression of GABA-mediated inhibitory postsynaptic currents [44]. Recently, APP was found to be involved in the regulation of L-type calcium channel function [45]. Loss of APP leads to increased levels of the L-type calcium channel subunit Cav1.2 in the striatum, which is associated with reduced GABAergic paired pulse inhibition and increased GABAergic post-tetanic potentiation [45]. However, these behavioral and electrophysiological impairments may not be caused by a gross loss of neurons or synapses because unbiased stereological quantification failed to detect any significant neuronal or synapse loss in aged $A P P \mathrm{KO}$ mice [42]. Also, attempts to examine dendritic spine density in $A P P \mathrm{KO}$ mice have revealed mixed results. Bittner et al. [46] reported that APP deletion leads to a twofold higher density of spines in apical dendrites of layer III and layer V neurons of the somatosensory cortex at 4-6 months of age, whereas Lee et al. [47] found a significant decrease in spine density in cortical layers II/III and hippocampal CA1 pyramidal neurons in 1-year-old APP KO mice compared with wildtype controls. This discrepancy may be due to a regionspecific effect, a contribution of aging and/or an adaptive mechanism. Nevertheless, additional study is warranted in this area.

The phenotypes of APLP2 and APLP1 single $\mathrm{KO}$ mice are also mild [6, 7]. APLP2 $\mathrm{KO}$ mice are viable, fertile and normal in size. No abnormalities were detected in tissues examined by histochemical analysis. APLP2 $\mathrm{KO}$ mice showed no difference from controls in forelimb strength as well as learning and memory performance in the Morris water maze and conditioned avoidance tasks. Similarly, APLP1 single KO mice are viable, fertile, but have a postnatal growth deficit. However, these mice show normal locomotor activity and forelimb grip strength $[6,7]$.

\section{Mice with combined KO of APP family members}

Though the phenotypes of $A P P$ family member single KOs are all relatively subtle, $A P P / A P L P 2$ or $A P L P 1 /$ $A P L P 2$ double $\mathrm{KO}(\mathrm{dKO})$ mice exhibit early postnatal lethality. This strongly indicates that functional redundancy exists among APP family members. Intriguingly, the $A P P / A P L P 1 \mathrm{dKO}$ mice are viable [7], suggesting a unique property specific to $A P L P 2$ that is required when
$A P P$ or $A P L P 1$ is absent.

In the PNS, APP and APLP2 play an essential yet redundant role in the formation and function of neuromuscular synapses. APP/APLP $2 \mathrm{dKO}$ mice have poorly formed NMJs, with excessive nerve growth and reduced apposition of pre- and postsynaptic elements. The number of synaptic vesicles at the presynaptic terminals is also reduced in parallel with impaired neurotransmitter release [48]. Moreover, study of the ultrastructure of the submandibular synapse also revealed significant reductions in synaptic vesicle density, active zone size and docked vesicle number per active zone in APP/APLP2 dKO mice [49].

Mice lacking all three APP family members survive through embryonic development but die shortly after birth [50]. Cranial abnormalities were seen in $81 \%$ of the triple KO mice while $68 \%$ showed cortical dysplasia resembling human type II lissencephaly. Additionally, the mutant mice showed partial loss of cortical Cajal Retzius cells at E18.5, suggesting a role for APP family members in neuronal migration and/or adhesion [50]. A very similar cortical dysplasia phenotype was also observed in mice that are double deficient for Fe65 and Fe65L1, a family of proteins that have been well known to interact with the APP cytoplasmic domain [51], suggesting an APP/Fe65 signaling complex mediating neuronal migration. The role of APP in neuronal migration/adhesion was further supported by the finding that acute knockdown of $A P P$ in rats using shRNA electroporation resulted in defective cortical plate entry and migration of neuronal precursor cells in the embryonic cortex [52].

\section{APP conditional $K O$}

To counter postnatal lethality and further dissect APP physiological functions, two conditional alleles of $A P P$ have been generated [31, 32]. Tissue-specific deletion of $A P P$ in either neurons or muscle in the $A P L P 2 \mathrm{KO}$ background resulted in neuromuscular defects similar to phenotypes seen in APP/APLP $2 \mathrm{dKO}$ mice, suggesting that APP expression is required in both motor neurons and muscle cells for the proper formation and function of neuromuscular synapses [31]. The authors propose that the trans-synaptic homotypic interaction of APP promotes neuromuscular synapse development. This was further supported by the synaptogenic properties of APP revealed by hippocampal and HEK293 mixed culture experiments [31]. Interestingly, muscle APP expression is required for the proper pre-synaptic localization of CHT (high-affinity choline transporter) and synaptic transmission, suggesting that trans-synaptic APP interaction is necessary for recruiting the presynaptic APP/CHT complex. Consistent with the role of APP in synaptic plastic- 
ity and synaptic function, a recent study that attempted to identify APP-interacting proteins using a tagged APP transgenic approach revealed a list of synaptic proteins including bassoon and neurexin [53]. Whether the transsynaptic interaction of APP is involved in the recruitment of these presynaptic molecules and how it coordinates with other synaptic adhesion complexes such as neuroligin/neurexin are exciting questions awaiting further investigation.

Knock-in models expressing distinct APP fragments and single amino acid mutations

As mentioned earlier, sequential proteolytic processing of APP generates three fragments: a large soluble ectodomain (APPs $\alpha$ or APPs $\beta$ ), a short peptide such as $\mathrm{P} 3$ or $\mathrm{A} \beta$ and the AICD. To investigate physiological functions exerted by these different APP fragments, two research groups have generated four different genetargeted APP mutant KI alleles, in which $\mathrm{A} \beta$ and $\mathrm{AICD}$ regions, are missing or mutated (Figure 3 ).

In order to determine the role of APPs $\alpha$ and APP Cterminal domain, the Müller group created two KI mouse lines [33]. The first expresses APPs $\alpha$ (APPs $\alpha$-ki) and the second expresses a C-terminal truncation of APP removing the highly conserved YENPTY motif (APPACT15$\mathrm{ki}$ ) by deletion of the last 15 aa residues (Figure $3 \mathrm{~B}$ and $3 \mathrm{C})$. Both of the lines have an overall reduction of mutant APP expression in both mRNA and protein levels, which is attributed to an effect of SV40 polyA cassette. In $A P P \triangle C T 15$-ki brains, even with a reduction of mutant APP expression of more than $50 \%$, there is a relatively higher percentage of cell surface APP and less A $\beta$ production compared to controls. This is consistent with the previous in vitro studies showing that the C-terminal region was involved in APP endocytosis and processing [54, 55].

In comparison with $A P P \mathrm{KO}$ mice, the $A P P s \alpha$-ki and $A P P \triangle C T 15$-ki mice appear to rescue a variety of phenotypes observed in $A P P \mathrm{KO}$ mice. For instance, the body and brain weight loss phenotype of $A P P \mathrm{KO}$ animals at different ages is largely rescued. Behaviorally, these KI mice do not exhibit any defects in grip strength test and water maze test. Electrophysiology experiments showed that LTP deficits observed in APP KO mice at 9-12 months were also corrected in both KI lines. Taken together, these results suggest that, similar to what was observed with APL-1 in the C. elegans model [15], the C-terminal region of APP may not be required for certain physiological functions of APP.

To further dissect the function of different APP domains, our research group has also generated two distinct KI lines. The first model expresses APPs $\beta$ with a
FLAG tag at the C-terminus named $A P P s \beta$-ki[18] (Figure $3 \mathrm{D})$. The second model, named $A P P / h A \beta / m u t C$ [19], expresses APP with a humanized $A \beta$ region, including three FAD mutations (Swedish, Arctic and London) to facilitate $A \beta$ production, and a frameshift mutation in the $\mathrm{C}$-terminus that deletes the last 39 aa residues of APP (Figure $3 \mathrm{E}$ ). Similar to the $A P P s \alpha$-ki and $A P P \triangle C T 15$-ki lines, $A P P s \beta$-ki and $A P P / h A \beta / m u t C$-ki mice do not show any obvious growth or anatomical deficits. As mentioned above, when $A P P \mathrm{KO}$ mice are bred to the APLP2 KO background, $A P P / A P L P 2$ dKO pups exhibit postnatal lethality. Similarly, when crossed with $A P L P 2 \mathrm{KO}$ mice, neither the $A P P s \beta$-ki nor $A P P / h A \beta / m u t C$-ki allele is able to rescue the lethality. Moreover, the deficits of NMJs observed in APP/APLP2 $\mathrm{dKO}$ pups, including aberrant apposition of presynaptic proteins with postsynaptic endplates and diffuse synaptic band width, also exist in $A P P s \beta^{k i / k i} / A P L P 2^{-/-}$and $A P P / h A \beta / m u t C^{k i / k i} / A P L P 2^{-/-}$ pups. Considering that neither of the KI alleles contains a functional APP C-terminal domain, our data clearly demonstrate a critical and indispensable role of the conserved C-terminal region of APP in early development.

Though our KI alleles are not able to rescue lethality, they do rescue certain gene expression changes caused by $A P P \mathrm{KO}$. In $A P P / A P L P 2 \mathrm{dKO}$ mice, the mRNA level of transthyretin (TTR) and Klotho is reduced [18]. However, the expression of TTR and Klotho is normal in the $A P P S \beta^{k i-} / A P L P 2^{-/}$pups. This finding indicates that soluble APP can modulate the expression of certain genes through a currently unknown pathway. TTR has been shown to have $A \beta$ binding ability [56-58] and Klotho has been extensively implicated in the aging process [59-61]. The enhancement of TTR and Klotho expression by APPs $\beta$ offers the fascinating possibility of a selfprotective mechanism in the APP processing pathway to counter the production and toxicity of $A \beta$ during aging.

When we crossed the $A P P / h A \beta /$ mutC KI line onto the PS1 M146V (a PS1 FAD mutation) KI background to accelerate $A \beta$ deposition, we found massive plaques in the hippocampus and cortex in mice over 1 year of age. This implies that amyloid pathogenesis could progress independently without the conserved C-terminal sequence [19].

The essential role of the highly conserved C-terminal region of APP in early development revealed by $A P P s \beta^{k i k i}$, $A P L P 2^{-/-}$and $A P P / h A \beta / m u t C^{k i / k i} / A P L P 2^{-/-}$mice was further confirmed by a recent study of Barbagallo et al. [34]. They generated a KI mouse with a single amino acid mutation at $\operatorname{Tyr}^{682}(\mathrm{Y} 682 \mathrm{G})$, and showed that, in the absence of APLP2 functional redundancy, the $\mathrm{Y} 682 \mathrm{G}$ mutation resulted in postnatal lethality and neuromuscular synapse defects similar to APP/APLP2-double-deficient mice [34, 

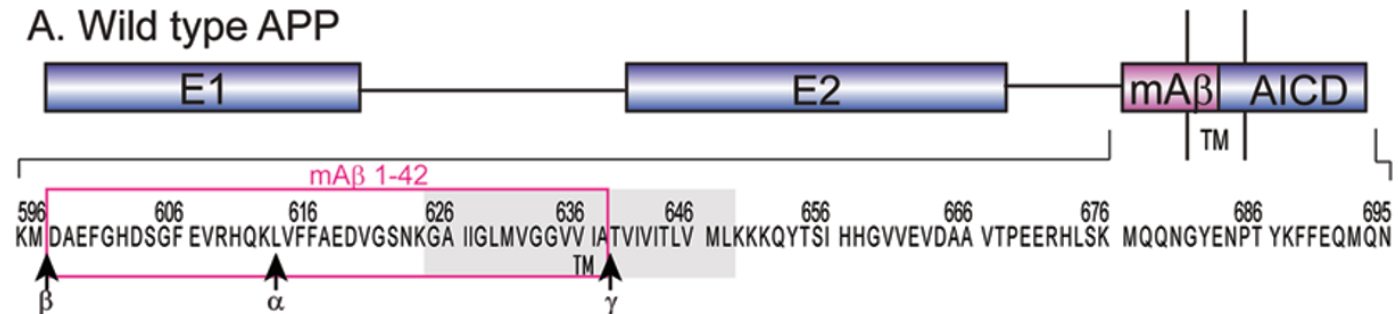

\section{B. APPs $\alpha-k i$}

E1

C. APP $\triangle \mathrm{CT} 15-\mathrm{ki}$
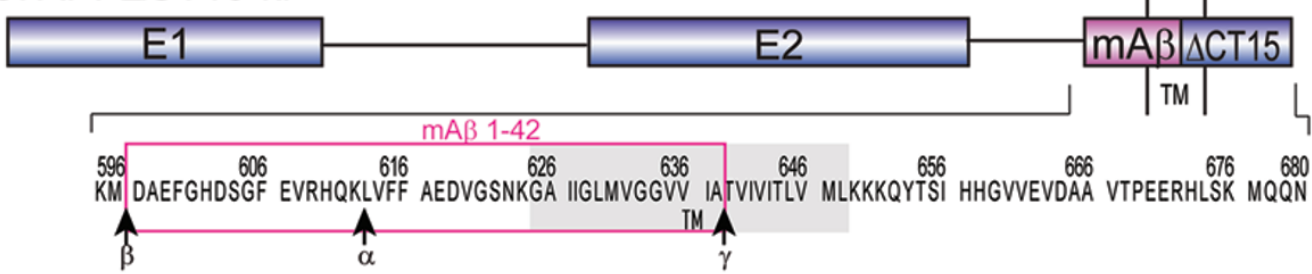

D. APPs $\beta$-ki

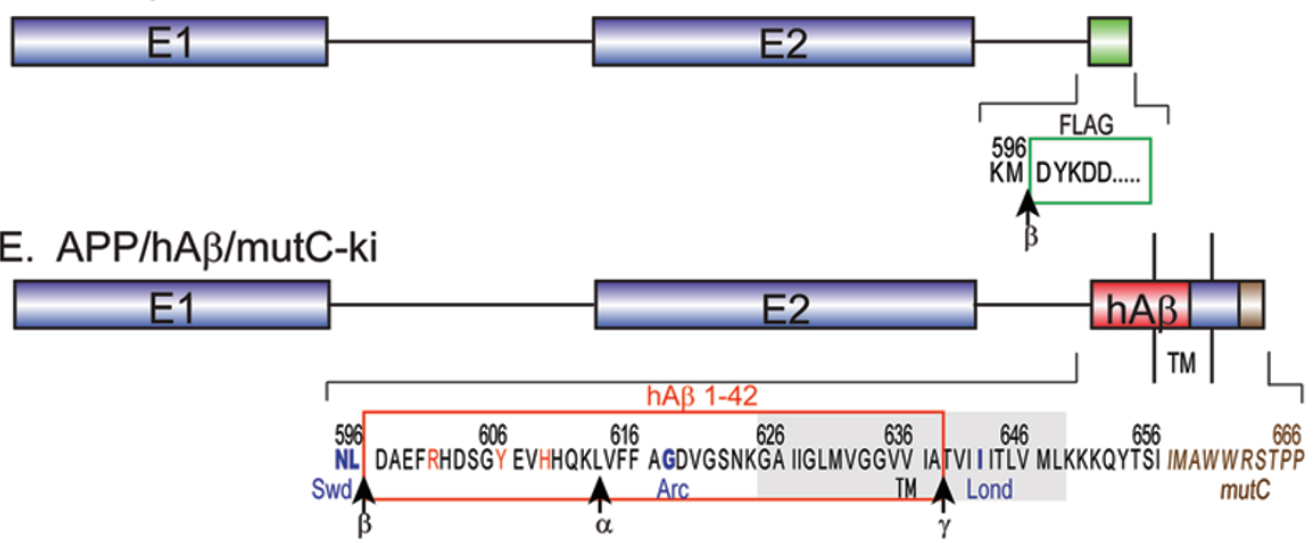

F. APPYG or APPTA-ki

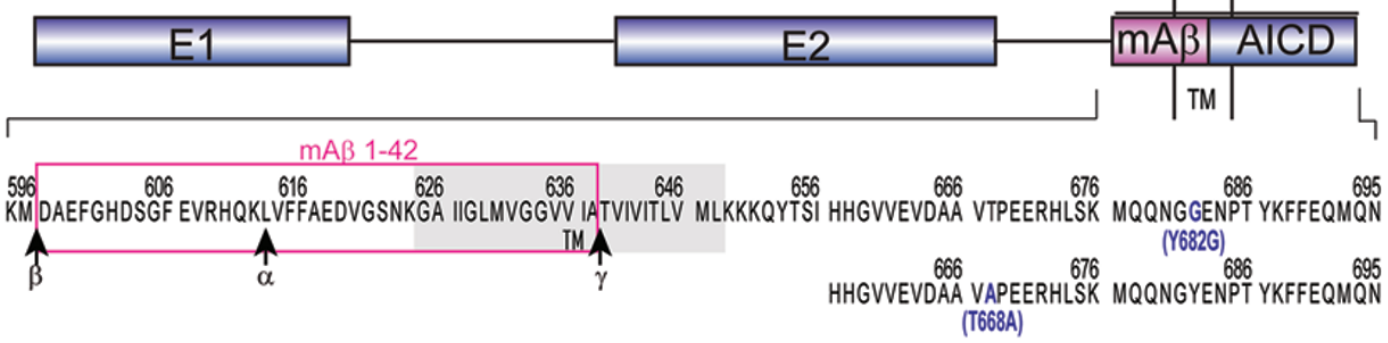

Figure 3 APP knock-in alleles expressing distinct APP fragments. (A) Wild-type APP695 with the mouse A $\beta$ region (mA $\beta$ ) framed in pink, and transmembrane area (TM) shaded in grey. AICD, APP intracellular domain. $\alpha, \beta$ and $\gamma$ are cleavage sites of the $\alpha-, \beta$, and $\gamma$-secretases, respectively. (B and C) APPs $\alpha$ and APP $\triangle$ CT15 knock-in alleles, respectively, reported by Ring et al. [33]. (D) APPs $\beta$ knock-in reported by Li et al. [18]. FLAG-tag sequence is framed in green. (E) APP/hA $\beta / m u t C$ knockin by Li et al. [19]. Humanized $A \beta$ region $(h A \beta)$ is framed in red, and the different residues between human and mouse sequence are also shown in red. Additional FAD mutations are bolded in blue. Swd, Arc and Lond, represent Swedish, Arctic and London mutations, respectively. The sequence resulting from a frame-shift mutation at $\mathrm{C}$-terminus is illustrated in brown. (F) $\mathrm{APP}^{\mathrm{YG}}$ and $\mathrm{APP}{ }^{\mathrm{TA}}$ knock-ins harbor APP Y682G and T668A mutations, respectively [34, 35]. 
62]. The importance of this $\operatorname{Tyr}^{682}$ site is strengthened by a parallel study, which found that a distinct mutation at a different Thr site, Thr668 (T668A), had no effect on both animal survival and formation of neuromuscular synapses $[34,35] . \mathrm{Tyr}^{682}$ is an essential residue of the $\mathrm{Y}^{682}$ ENPTY $^{687}$ motif, which is the docking site for numerous cytosolic proteins [63]. Some APP interactors require phosphorylated $\operatorname{Tyr}^{682}$ [64-67], whereas others require non-phosphorylated $\mathrm{Tyr}^{682}$ [68]. This leads to questions in regards to how the selective phosphorylation state of Tyr682 is regulated and their corresponding functional consequences.

In summary, these different KI lines expressing different segments of $A P P$ have revealed that APP is involved in multiple functions. Some of these functions are carried out by APP N-terminal ectodomain alone without the APP C-terminal intracellular domain. However, the AICD, especially the YENPTY motif, which is well conserved from worms to humans, plays a critical role in developmental regulation in mice. Finally, A $\beta$ aggregation and amyloid deposition can proceed without the APP C-terminus, implying that APP physiological functions could be genetically uncoupled with AD pathogenesis.

\section{APP FAD mutant KI models}

Many APP transgenic models expressing APP with FAD mutations under the control of a robust exogenous promoter have been generated and have provided us with valuable knowledge about $\mathrm{AD}$ pathogenesis, especially $A \beta$ plaque deposition. However, in order to accelerate plaque development, transgenic mice usually overexpress mutant APP at a very high level. For instance, a commonly used transgenic line, $\mathrm{Tg} 2576$, overexpresses APP to almost sixfold using the hamster prion promoter [69]. Considering the crucial and various functions of APP in nervous system development, this provokes the question of whether the memory and behavioral defects observed in $\mathrm{AD}$-transgenic mice are due to $\mathrm{A} \beta$ pathology or simply APP overexpression.

To avoid the complications of overexpression and build a more physiologically relevant model, several labs generated different FAD APP KI lines by introducing human FAD mutations and/or humanized $\mathrm{A} \beta$ to the endogenous mouse $A P P$ gene. Compared to traditional transgenic models, $A P P \mathrm{KI}$ mice exhibit a number of advantages. Since the KI allele is under the native $A P P$ promoter control, the amount of APP expression remains at physiological level. For the same reason, the temporal and spatial expression patterns of mutant APP are not affected. In contrast to the transgenic lines in which the wild-type mouse $A P P$ gene is still intact, where mouse APP and A $\beta$ may complicate the phenotype, the KI models have mouse $A \beta$ replaced with the human $A \beta$ sequence.

One FAD KI model was developed by Reaume et al., [70] who generated $A P P^{N L h / N L h}$ mice bearing the Swedish FAD mutation (K670N/M671L) with a humanized A $\beta$ sequence expressed at endogenous levels. Amyloidogenic $\beta$-secretase cleavage of this mutant APP is accurate and also enhanced, while the non-amyloidogenic processing is repressed. Human $A \beta$ production is significantly increased in these mice, a ninefold increase compared to normal human brain tissue [70]. Though this $A P P \mathrm{KI}$ model overproduces human $\mathrm{A} \beta 40$ and $\mathrm{A} \beta 42, \mathrm{~A} \beta$ plaque deposition was not detectable [71]. Later, the $A P P^{N L h}$ ${ }^{N L h}$ strain was crossed with the $P S-1^{P 264 L / P 264 L}$ line (a PS1 FAD mutant KI line) to generate the $A P P^{N L h / N L h} / P S-1^{P 264 L /}$ ${ }_{P 264 L}$ double KI (DKI) model [71]. $A P P^{N L h / N L h} / P S-1^{P 264 L /}$ ${ }^{P 264 L}$ DKI animals exhibit elevated levels of $A \beta 42$ and initial $A \beta$ deposition begins at 6 months of age. $A \beta$ deposition at 6 months was predominately seen in the cerebral cortex with the majority of deposits found in the frontal cortex, followed by the parietal cortex [71]. Microarray analysis was performed to compare the gene expression profile changes between $A P P^{N L h / N L h} / P S-1^{P 264 L / P 264 L}$ animals and two transgenic models, Tg2576/PS-1 $1^{\mathrm{P} 264 \mathrm{~L} /+}$ and Tg2576/PS-1 ${ }^{\text {P264L/P264L }}$, both before and after detectable A $\beta$ deposition [72]. Gene expression difference was analyzed in $A P P^{N L h / N L h} / P S-1^{P 264 L / P 264 L}$ DKI animals and their wild-type littermates at 2 months of age, when plaques in DKI brains are absent, and at 18 months of age, when the DKI cortical plaque load is $3.2 \%$. Similar experiments were also performed to compare expression changes in Tg2576/PS-1 $1^{\mathrm{P} 264 \mathrm{~L} /+}$, Tg2576/PS-1 $1^{\mathrm{P} 264 \mathrm{~L} / \mathrm{P} 264 \mathrm{~L}}$ and nontransgenic controls (non-Tg/PS-1 $1^{+/+}$) at 2 months of age, when $\mathrm{Tg} 2576 / \mathrm{PS}-1^{\mathrm{P} 264 \mathrm{~L} / \mathrm{t}}$ had no plaques and the cortical plaque load of $\mathrm{Tg} 2576 / \mathrm{PS}-1^{\mathrm{P} 264 \mathrm{~L} / \mathrm{P} 264 \mathrm{~L}}$ is $0.09 \%$, and at 12 months of age, when the plaque load of Tg2576/PS$1^{\mathrm{P} 264 \mathrm{~L} /+}$ and Tg2576/PS- $1^{\mathrm{P} 264 \mathrm{~L} / \mathrm{P} 264 \mathrm{~L}}$ was $10.6 \%$ and $25.8 \%$, respectively. In young animals before $\mathrm{A} \beta$ deposition, the DKI animals do not share any altered gene expression when compared with the two transgenic models, which is possibly due to APP overexpression in transgenic models and/or a genetic background difference. However, there are a number of common changes found in the three models with $\mathrm{A} \beta$ deposition and many of these changes are also found in human AD brains [72]. This finding strongly supports this DKI animal model as a valuable $\mathrm{AD}$ research tool. Chang et al. [73] performed electrophysiological and behavioral studies with $A P P^{N L h / N L h} / P S$ $1^{P 264 L / P 264 L}$ animals. DKI animals showed an age-related decrease of AMPA receptor-mediated evoked currents and spontaneous miniature currents. The downregulation of synaptic AMPA receptor is confirmed by electron 
microscopic study. DKI animals also exhibit age-related deficits in bidirectional plasticity seen during analysis of LTP and LTD in these mice as well as memory flexibility when examined by Morris water maze. Additionally, long-lasting and selective impairment in adult hippocampal neurogenesis is found in 9-18 months old $A P P^{N L h / N L h} /$ $P S-1^{P 264 L / P 264 L}$ DKI animals, while the olfactory bulb neurogenic system is not affected. The number of MCM2positive neural stem and progenitor cells is decreased by 3 -fold compared to controls and doublecortin-positive neuroblasts are decreased by twofold as well. This neurogenesis impairment phenotype may be explained by $\mathrm{A} \beta$ deposition-induced microglia activation and neuroinflammation [74].

Another similar FAD mutant $A P P$ KI line was generated by Kohler et al. [75], which includes the humanized
A $\beta$ sequence containing both Swedish (K670N/M671L) and London $(\mathrm{V} 717 \mathrm{~F})$ mutations. $A P P^{S L / S L}$ single KI animals do not show any $\mathrm{A} \beta$ deposits. Once this strain was crossed to an FAD $P S 1$ transgenic strain $\left(P S 1^{M 146 L}\right.$ $\left.{ }^{t g}\right)$, then $A \beta$ deposition occurred in a similar pattern to APP transgenic animals. However, the $A \beta$ deposits in $A P P^{S L / S L} / P S 1^{M 146 L-t g}$ mice began much later and developed more slowly than APP transgenic animals, with no apparent neurodegeneration [75]. Further characterization revealed that $A P P^{S L / S L} / P S 1^{M 146 L-t g}$ mice have increased levels of $A \beta$ peptides at 10 months of age and amyloid plaques at 14 months of age. Microdialysis showed that the hippocampal extracellular acetylcholine (ACh) levels of 15-27 months old $A P P^{S L / S L} / P S 1^{M 146 L-t g}$ mice are slightly but significantly reduced. However, there were no major changes found in stimulated $\mathrm{ACh}$ release and overall

Table 1 Summary and comparison of APP knock-in mouse models

\begin{tabular}{|c|c|c|c|c|}
\hline APP allele & APP knock-in mutation(s) & Mouse model & $\mathrm{A} \beta$ Plaque & Major findings \\
\hline $\mathrm{APP}^{\mathrm{NLh}}$ & $\begin{array}{l}\text { K670N/M671L } \\
\text { (Swedish mutation) } \\
\text { Humanized A } \beta\end{array}$ & $\mathrm{APP}^{\mathrm{NLh} / \mathrm{NLh}}$ & No & $\begin{array}{l}\text { The human } \mathrm{A} \beta \text { production is } 9 \text {-fold higher } \\
\text { than normal human brain tissue [70]. }\end{array}$ \\
\hline $\mathrm{APP}^{\mathrm{NLh}}$ & $\begin{array}{l}\text { K670N/M671L } \\
\text { (Swedish mutation) } \\
\text { Humanized A } \beta\end{array}$ & $\begin{array}{l}\mathrm{APP}^{\mathrm{NLh} / \mathrm{NLh}} / \\
\mathrm{PS}-1^{\mathrm{P} 264 \mathrm{~L} / \mathrm{P} 264 \mathrm{~L}}\end{array}$ & Yes & $\begin{array}{l}\text { 1. A } \beta \text { deposition begins at } 6 \mathrm{~m} / \mathrm{o}[71] \text {. } \\
\text { 2. The altered gene expression profile of AP- } \\
\mathrm{P}^{\mathrm{NLh} / \mathrm{NLh}} / \mathrm{PS}-1^{\mathrm{P} 264 \mathrm{~L} / \mathrm{P} 64 \mathrm{~L}} \text { animals after plaque } \\
\text { deposition is shared by two transgenic } \\
\text { models as well as human AD brains [72]. } \\
\text { 3. APP }{ }^{\mathrm{NLh} / \mathrm{NLh}} / \mathrm{PS}-1^{\mathrm{P} 264 \mathrm{~L} / \mathrm{P} 264 \mathrm{~L}} \text { animals show } \\
\text { age-related decreasing of AMPA receptor } \\
\text { number and activity. They also exhibit age- } \\
\text { related deficits in LTP and LTD studies as } \\
\text { well as memory impairment in water maze } \\
\text { test [73]. } \\
\text { 4. APP } \\
\text { lasting and selective impairment in adult } \\
\text { hippocampal neurogenesis at 9-18 m/o [74]. }\end{array}$ \\
\hline $\mathrm{APP}^{\mathrm{SL}}$ & $\begin{array}{l}\text { K670N/M671L; } \\
\text { (Swedish mutation) } \\
\text { V717F (London mutation) } \\
\text { Humanized A } \beta\end{array}$ & $\begin{array}{l}\mathrm{APP}^{\mathrm{SL} / \mathrm{SL}} / \\
\mathrm{PS}^{\mathrm{M} 146 \mathrm{~L}-\mathrm{tg}}\end{array}$ & Yes & $\begin{array}{l}\text { 1. } \mathrm{APP}^{\mathrm{SL} / \mathrm{SL}} \text { single knock-in animals do not } \\
\text { show any } \mathrm{A} \beta \text { deposits }[75] \text {. } \\
\text { 2. } \mathrm{APP}^{\mathrm{SL} / \mathrm{SL}} / \mathrm{PS} 1^{\mathrm{M} 146 \mathrm{~L}-\mathrm{tg}} \text { mice have increased } \\
\text { levels of } \mathrm{A} \beta \text { peptides at } 10 \mathrm{~m} / \mathrm{o} \text { and amyloid } \\
\text { plaques at } 14 \mathrm{~m} / \mathrm{o}[75] . \\
\text { 3. Microdialysis study indicates that the } \\
\text { hippocampal extracellular acetylcholine } \\
\text { (ACh) levels of } 15-27 \mathrm{~m} / \mathrm{o} \text { APP }{ }^{\mathrm{SL} / \mathrm{SL}} / \mathrm{PS} 1^{\mathrm{M} 146 \mathrm{~L}-\mathrm{tg}} \\
\text { mice are slightly but significantly reduced [76]. }\end{array}$ \\
\hline
\end{tabular}


central cholinergic function was not affected [76].

The KI model attempting to genetically mimic human FAD to the greatest extent was generated by Kawasumi et al. [77]. This strain contains an APP V642I mutant KI allele without modifying the mouse $\mathrm{A} \beta$ sequence, which was then studied in a heterozygous state. APP V642I/+ animals appear normal compared to their wild-type littermates up to 2.5 years of age. However, their long-term spatial memory is significantly impaired and acquisition of spatial memory is slightly affected. Histologically, the ratio of $A \beta 42$ (43)/A $\beta 40$ is greatly increased in mutants, but there are no plaques or neurofibrillary tangles in the mutant brains.

All the mouse models mentioned above are summarized in Table 1.

\section{Concluding Remarks}

In vivo models of APP family members provide us with a considerable amount of insight into the physiological function of APP. It is now well known that APP and its homologs are important for early developmental events, such as mediating cell adhesion, cell migration and synaptogenesis. These models also highlight several intriguing directions for future study. First, full-length APP is vital for neuromuscular synapse assembly and possibly central synaptogenesis. Second, APPs $\beta$, independent of full-length APP, can regulate the expression of certain genes like TTR and Klotho. The receptor mediating such an event remains to be identified. Third, $A P P /$ $A P L P 2$ germline $\mathrm{dKO}$ animals are early postnatal lethal, whereas animals with a conditional deletion of $A P P$ only in the central nervous system (CNS) on an APLP2-null background are viable. This finding strongly suggests that APP has vital, yet undiscovered, functions outside the CNS. Finally, it is known that APP is strongly upregulated in brains that have experienced TBI in both human patients and in mice. TBI-induced APP upregulation may contribute to higher $\mathrm{A} \beta$ production and increased risk of AD in later life. Since studies in Drosophila demonstrated that the mortality rate of Appl-deficient flies is higher than controls after TBI treatment, it will be extremely interesting to know how $A P P / A P L P 2$ conditional $\mathrm{KO}$ animals survive TBI and to further dissect the functional role of APP in post-TBI brain repair.

All of the FAD APP KI AD mouse models share mild phenotypes and pathological manifestations. To generate plaque pathology, both an APP KI mutation and an FAD PS1 allele are needed. Considering that a heterozygous APP FAD mutation is able to trigger early onset $\mathrm{AD}$ in humans, the effects of these mutations in mice are considerably weaker. This difference may be due to the short-life span of mice and the intrinsic physiological differences between humans and mice. Nevertheless, these $A P P \mathrm{KI}$ models provide us with an alternative platform and a more physiologically relevant disease model to study human AD. More comprehensive and sensitive assays will be required for better characterizing $A P P \mathrm{KI}$ mice and consequently $\mathrm{AD}$ pathogenesis in the future.

\section{Acknowledgments}

The authors' work cited in this review was supported by grants from NIH (AG020670, AG032051 and AG033467) and the American Health and Assistance Foundation (A2008-052).

\section{References}

1 Goldgaber D, Lerman MI, McBride OW, Saffiotti U, Gajdusek DC. Characterization and chromosomal localization of a cDNA encoding brain amyloid of Alzheimer's disease. Science 1987; 235:877-880.

2 Kang J, Lemaire HG, Unterbeck A, et al. The precursor of Alzheimer's disease amyloid A4 protein resembles a cell-surface receptor. Nature 1987; 325:733-736.

3 Tanzi RE, Gusella JF, Watkins PC, et al. Amyloid beta protein gene: cDNA, mRNA distribution, and genetic linkage near the Alzheimer locus. Science 1987; 235:880-884.

4 Chow VW, Mattson MP, Wong PC, Gleichmann M. An overview of APP processing enzymes and products. Neuromolecular Med 2010; 12:1-12.

5 Weidemann A, Eggert S, Reinhard FB, et al. A novel epsiloncleavage within the transmembrane domain of the Alzheimer amyloid precursor protein demonstrates homology with Notch processing. Biochemistry 2002; 41:2825-2835.

6 von Koch CS, Zheng H, Chen $\mathrm{H}$, et al. Generation of APLP2 KO mice and early postnatal lethality in APLP2/APP double KO mice. Neurobiol Aging 1997; 18:661-669.

7 Heber S, Herms J, Gajic V, et al. Mice with combined gene knock-outs reveal essential and partially redundant functions of amyloid precursor protein family members. $J$ Neurosci 2000; 20:7951-7963.

8 Armstrong RA, Lantos PL, Cairns NJ. What determines the molecular composition of abnormal protein aggregates in neurodegenerative disease? Neuropathology 2008; 28:351-365.

9 Korczyn AD. The amyloid cascade hypothesis. Alzheimers Dement 2008; 4:176-178.

10 Zheng H, Koo EH. The amyloid precursor protein: beyond amyloid. Mol Neurodegener 2006; 1:5.

11 Daigle I, Li C. apl-1, a Caenorhabditis elegans gene encoding a protein related to the human beta-amyloid protein precursor. Proc Natl Acad Sci USA 1993; 90:12045-12049.

12 Slunt HH, Thinakaran G, Von Koch C, Lo AC, Tanzi RE, Sisodia SS. Expression of a ubiquitous, cross-reactive homologue of the mouse beta-amyloid precursor protein (APP). $J$ Biol Chem 1994; 269:2637-2644.

13 Wasco W, Bupp K, Magendantz M, Gusella JF, Tanzi RE, Solomon F. Identification of a mouse brain cDNA that encodes a protein related to the Alzheimer disease-associated amyloid beta protein precursor. Proc Natl Acad Sci USA 1992; 
89:10758-10762.

14 Wasco W, Gurubhagavatula S, Paradis MD, et al. Isolation and characterization of APLP2 encoding a homologue of the Alzheimer's associated amyloid beta protein precursor. Nat Genet 1993; 5:95-100.

15 Hornsten A, Lieberthal J, Fadia S, et al. APL-1, a Caenorhabditis elegans protein related to the human beta-amyloid precursor protein, is essential for viability. Proc Natl Acad Sci USA 2007; 104:1971-1976. Epub 2007 Jan 1931.

16 Wiese M, Antebi A, Zheng H. Intracellular trafficking and synaptic function of APL-1 in Caenorhabditis elegans. PLoS ONE 2010; 5:e12790..

17 Hada K, Asahina M, Hasegawa H, Kanaho Y, Slack FJ, Niwa $\mathrm{R}$. The nuclear receptor gene $n h r-25$ plays multiple roles in the Caenorhabditis elegans heterochronic gene network to control the larva-to-adult transition. Dev Biol 2010; 344:1100-1109.

18 Li H, Wang B, Wang Z, et al. Soluble amyloid precursor protein (APP) regulates transthyretin and Klotho gene expression without rescuing the essential function of APP. Proc Natl Acad Sci USA 2010; 107:17362-17367.

19 Li H, Wang Z, Wang B, et al. Genetic dissection of the amyloid precursor protein in developmental function and amyloid pathogenesis. J Biol Chem 2010; 285:30598-30605.

20 Luo L, Tully T, White K. Human amyloid precursor protein ameliorates behavioral deficit of flies deleted for Appl gene. Neuron 1992; 9:595-605.

21 Gunawardena S, Goldstein LS. Disruption of axonal transport and neuronal viability by amyloid precursor protein mutations in Drosophila. Neuron 2001; 32:389-401.

22 Torroja L, Packard M, Gorczyca M, White K, Budnik V. The Drosophila beta-amyloid precursor protein homolog promotes synapse differentiation at the neuromuscular junction. $J \mathrm{Neu}$ rosci 1999; 19:7793-7803.

23 Ashley J, Packard M, Ataman B, Budnik V. Fasciclin II signals new synapse formation through amyloid precursor protein and the scaffolding protein dX11/Mint. J Neurosci 2005; 25:59435955.

24 Merdes G, Soba P, Loewer A, Bilic MV, Beyreuther K, Paro R. Interference of human and Drosophila APP and APP-like proteins with PNS development in Drosophila. EMBO J 2004; 23:4082-4095.

25 Leyssen M, Ayaz D, Hebert SS, Reeve S, De Strooper B, Hassan BA. Amyloid precursor protein promotes post-developmental neurite arborization in the Drosophila brain. EMBO J 2005; 24:2944-2955.

26 Joshi P, Liang JO, DiMonte K, Sullivan J, Pimplikar SW. Amyloid precursor protein is required for convergent-extension movements during Zebrafish development. Dev Biol 2009; 335:1-11.

27 Lee JA, Cole GJ. Generation of transgenic zebrafish expressing green fluorescent protein under control of zebrafish amyloid precursor protein gene regulatory elements. Zebrafish 2007; 4:277-286.

28 Zheng H, Jiang M, Trumbauer ME, et al. beta-Amyloid precursor protein-deficient mice show reactive gliosis and decreased locomotor activity. Cell 1995; 81:525-531.

29 Li ZW, Stark G, Gotz J, et al. Generation of mice with a 200$\mathrm{kb}$ amyloid precursor protein gene deletion by Cre recombinase-mediated site-specific recombination in embryonic stem cells. Proc Natl Acad Sci USA 1996; 93:6158-6162.

30 Muller U, Cristina N, Li ZW, et al. Behavioral and anatomical deficits in mice homozygous for a modified beta-amyloid precursor protein gene. Cell 1994; 79:755-765.

31 Wang Z, Wang B, Yang L, et al. Presynaptic and postsynaptic interaction of the amyloid precursor protein promotes peripheral and central synaptogenesis. J Neurosci 2009; 29:1078810801 .

32 Mallm JP, Tschape JA, Hick M, Filippov MA, Muller UC. Generation of conditional null alleles for $A P P$ and $A P L P 2$. Genesis 2010; 48:200-206.

33 Ring S, Weyer SW, Kilian SB, et al. The secreted beta-amyloid precursor protein ectodomain APPs alpha is sufficient to rescue the anatomical, behavioral, and electrophysiological abnormalities of APP-deficient mice. J Neurosci 2007; 27:78177826.

34 Barbagallo AP, Weldon R, Tamayev R, et al. $\operatorname{Tyr}(682)$ in the intracellular domain of APP regulates amyloidogenic APP processing in vivo. PLoS One 2010; 5:e15503.

35 Barbagallo AP, Wang Z, Zheng H, D'Adamio L. The intracellular threonine of amyloid precursor protein that is essential for docking of pin 1 is despensable for developmental function. PLoS One 2011; 6:e18006.

36 Steinbach JP, Muller U, Leist M, Li ZW, Nicotera P, Aguzzi A. Hypersensitivity to seizures in beta-amyloid precursor protein deficient mice. Cell Death Differ 1998; 5:858-866.

37 White AR, Multhaup G, Maher F, et al. The Alzheimer's disease amyloid precursor protein modulates copper-induced toxicity and oxidative stress in primary neuronal cultures. $J$ Neurosci 1999; 19:9170-9179.

38 Duce JA, Tsatsanis A, Cater MA, et al. Iron-export ferroxidase activity of beta-amyloid precursor protein is inhibited by zinc in Alzheimer's disease. Cell 2010; 142:857-867.

39 Grimm MO, Grimm HS, Patzold AJ, et al. Regulation of cholesterol and sphingomyelin metabolism by amyloid-beta and presenilin. Nat Cell Biol 2005; 7:1118-1123.

40 Needham BE, Wlodek ME, Ciccotosto GD, et al. Identification of the Alzheimer's disease amyloid precursor protein (APP) and its homologue APLP2 as essential modulators of glucose and insulin homeostasis and growth. J Pathol 2008; 215:155163.

41 Dawson GR, Seabrook GR, Zheng H, et al. Age-related cognitive deficits, impaired long-term potentiation and reduction in synaptic marker density in mice lacking the beta-amyloid precursor protein. Neuroscience 1999; 90:1-13.

42 Phinney AL, Calhoun ME, Wolfer DP, Lipp HP, Zheng H, Jucker M. No hippocampal neuron or synaptic bouton loss in learning-impaired aged beta-amyloid precursor protein-null mice. Neuroscience 1999; 90:1207-1216.

43 Senechal Y, Kelly PH, Dev KK. Amyloid precursor protein knockout mice show age-dependent deficits in passive avoidance learning. Behav Brain Res 2008; 186:126-132.

44 Seabrook GR, Smith DW, Bowery BJ, et al. Mechanisms contributing to the deficits in hippocampal synaptic plasticity in mice lacking amyloid precursor protein. Neuropharmacology 1999; 38:349-359.

45 Yang L, Wang Z, Wang B, Justice NJ, Zheng H. Amyloid precursor protein regulates Cav1.2 L-type calcium channel levels and function to influence GABAergic short-term plasticity. $J$ 
Neurosci 2009; 29:15660-15668.

46 Bittner T, Fuhrmann M, Burgold S, et al. Gamma-secretase inhibition reduces spine density in vivo via an amyloid precursor protein-dependent pathway. J Neurosci 2009; 29:10405-10409.

47 Lee KJ, Moussa CE, Lee Y, et al. Beta amyloid-independent role of amyloid precursor protein in generation and maintenance of dendritic spines. Neuroscience 2010; 169:344-356.

48 Wang P, Yang G, Mosier DR, et al. Defective neuromuscular synapses in mice lacking amyloid precursor protein (APP) and APP-Like protein 2. J Neurosci 2005; 25:1219-1225.

49 Yang G, Gong YD, Gong K, et al. Reduced synaptic vesicle density and active zone size in mice lacking amyloid precursor protein (APP) and APP-like protein 2. Neurosci Lett 2005; 384:66-71.

50 Herms J, Anliker B, Heber S, et al. Cortical dysplasia resembling human type 2 lissencephaly in mice lacking all three APP family members. EMBO J 2004; 23:4106-4115.

51 Guenette S, Chang Y, Hiesberger T, et al. Essential roles for the FE65 amyloid precursor protein-interacting proteins in brain development. EMBO J 2006; 25:420-431.

52 Young-Pearse TL, Bai J, Chang R, Zheng JB, Loturco JJ, Selkoe DJ. A critical function for amyloid precursor protein in neuronal migration revealed by in utero RNA interference. $J$ Neurosci 2007; 27:14459-14469.

53 Norstrom EM, Zhang C, Tanzi R, Sisodia SS. Identification of NEEP2 1 as a ss-amyloid precursor protein-interacting protein in vivo that modulates amyloidogenic processing in vitro. $J$ Neurosci 2010; 30:15677-15685.

54 Koo EH, Squazzo SL, Selkoe DJ, Koo CH. Trafficking of cellsurface amyloid beta-protein precursor. I. Secretion, endocytosis and recycling as detected by labeled monoclonal antibody. J Cell Sci 1996; 109:991-998.

55 Perez RG, Soriano S, Hayes JD, et al. Mutagenesis identifies new signals for beta-amyloid precursor protein endocytosis, turnover, and the generation of secreted fragments, including Abeta42. J Biol Chem 1999; 274:18851-18856.

56 Schwarzman AL, Gregori L, Vitek MP, et al. Transthyretin sequesters amyloid beta protein and prevents amyloid formation. Proc Natl Acad Sci USA 1994; 91:8368-8372.

57 Choi SH, Leight SN, Lee VM, et al. Accelerated Abeta deposition in APPswe/PS1deltaE9 mice with hemizygous deletions of TTR (transthyretin). J Neurosci 2007; 27:7006-7010.

58 Buxbaum JN, Ye Z, Reixach N, et al. Transthyretin protects Alzheimer's mice from the behavioral and biochemical effects of Abeta toxicity. Proc Natl Acad Sci USA 2008; 105:26812686.

59 Kuro-o M, Matsumura Y, Aizawa H, et al. Mutation of the mouse klotho gene leads to a syndrome resembling ageing. Nature 1997; 390:45-51.

60 Kurosu H, Yamamoto M, Clark JD, et al. Suppression of aging in mice by the hormone Klotho. Science 2005; 309:1829-1833.

61 Imura A, Tsuji Y, Murata M, et al. alpha-Klotho as a regulator of calcium homeostasis. Science 2007; 316:1615-1618.

62 Barbagallo AP, Wang Z, Zheng H, D'Adamio L. A single tyrosine residue in the amyloid precursor protein intracellular domain is essential for developmental function. $J$ Biol Chem 2011; 286:8717-8721.

63 King GD, Turner SR. Adaptor protein interactions: modulators of amyloid precursor protein metabolism and Alzheimer's dis- ease risk? Exp Neurol 2004; 185:208-219.

64 Zhou D, Noviello C, D'Ambrosio C, Scaloni A, D'Adamio L. Growth factor receptor-bound protein 2 interaction with the tyrosine-phosphorylated tail of amyloid beta precursor protein is mediated by its Src homology 2 domain. J Biol Chem 2004; 279:25374-25380.

65 Russo C, Dolcini V, Salis S, et al. Signal transduction through tyrosine-phosphorylated C-terminal fragments of amyloid precursor protein via an enhanced interaction with Shc/Grb2 adaptor proteins in reactive astrocytes of Alzheimer's disease brain. J Biol Chem 2002; 277:35282-35288.

66 Tarr PE, Roncarati R, Pelicci G, Pelicci PG, D'Adamio L. Tyrosine phosphorylation of the beta-amyloid precursor protein cytoplasmic tail promotes interaction with Shc. $J$ Biol Chem 2002; 277:16798-16804.

67 Tamayev R, Zhou D, D'Adamio L. The interactome of the amyloid beta precursor protein family members is shaped by phosphorylation of their intracellular domains. Mol Neurodegener 2009; 4:28.

68 Zhou D, Zambrano N, Russo T, D’Adamio L. Phosphorylation of a tyrosine in the amyloid-beta protein precursor intracellular domain inhibits Fe65 binding and signaling. J Alzheimers Dis 2009; 16:301-307.

69 Hsiao K, Chapman P, Nilsen S, et al. Correlative memory deficits, Abeta elevation, and amyloid plaques in transgenic mice. Science 1996; 274:99-102.

70 Reaume AG, Howland DS, Trusko SP, et al. Enhanced amyloidogenic processing of the beta-amyloid precursor protein in gene-targeted mice bearing the Swedish familial Alzheimer's disease mutations and a 'humanized' Abeta sequence. $J$ Biol Chem 1996; 271:23380-23388.

71 Flood DG, Reaume AG, Dorfman KS, et al. FAD mutant PS-1 gene-targeted mice: increased A beta 42 and A beta deposition without APP overproduction. Neurobiol Aging 2002; 23:335348.

72 Wu ZL, Ciallella JR, Flood DG, O'Kane TM, BozyczkoCoyne D, Savage MJ. Comparative analysis of cortical gene expression in mouse models of Alzheimer's disease. Neurobiol Aging 2006; 27:377-386.

73 Chang EH, Savage MJ, Flood DG, et al. AMPA receptor downscaling at the onset of Alzheimer's disease pathology in double knockin mice. Proc Natl Acad Sci USA 2006; 103:3410-3415.

74 Zhang C, McNeil E, Dressler L, Siman R. Long-lasting impairment in hippocampal neurogenesis associated with amyloid deposition in a knock-in mouse model of familial Alzheimer's disease. Exp Neurol 2007; 204:77-87.

75 Kohler C, Ebert U, Baumann K, Schroder H. Alzheimer's disease-like neuropathology of gene-targeted APP-SLxPS1mut mice expressing the amyloid precursor protein at endogenous levels. Neurobiol Dis 2005; 20:528-540.

76 Hartmann J, Erb C, Ebert U, et al. Central cholinergic functions in human amyloid precursor protein knock-in/presenilin-1 transgenic mice. Neuroscience 2004; 125:1009-1017.

77 Kawasumi M, Chiba T, Yamada M, et al. Targeted introduction of V642I mutation in amyloid precursor protein gene causes functional abnormality resembling early stage of Alzheimer's disease in aged mice. Eur J Neurosci 2004; 19:2826-2838. 